\title{
Non contiguous-finished genome sequence and description of Dielma fastidiosa gen. nov., sp. nov., a new member of the Family Erysipelotrichaceae
}

\author{
Dhamodharan Ramasamy ${ }^{1}$, Jean-Christophe Lagier ${ }^{1}$, Thi Tien Nguyen ${ }^{1}$, Didier Raoult ${ }^{1}$ and \\ Pierre-Edouard Fournier ${ }^{1}$ * \\ ${ }^{1}$ Aix-Marseille Université, URMITE, Faculté de médecine, Marseille, France \\ *Corresponding author: Pierre-Edouard Fournier (pierre-edouard.fournier@univmed.fr) \\ Keywords: Dielma fastidiosa, Genome, Culturomics, Taxono-genomics
}

Dielma fastidiosa strain JC13 gen. nov., sp. nov. is the type strain of D. fastidiosa gen. nov., sp. nov., the type species of a new genus within the family Erysipelotrichaceae. This strain, whose draft genome is described here, was isolated from the fecal flora of a healthy 16-year-old male Senegalese volunteer. $D$. fastidiosa is a Gram-negative anaerobic rod. Here we describe the features of this organism, together with the complete genome sequence and annotation. The 3,574,031 bp long genome comprises a 3,556,241-bp chromosome and a 17,790-bp plasmid. The chromosome contains 3,441 protein-coding and 50 RNA genes, including 3 rRNA genes, whereas the plasmid contains 17 protein-coding genes.

\section{Introduction}

Dielma fastidiosa strain JC13 ${ }^{\mathrm{T}}$ (CSUR P149 / DSM 26099 ) is the type strain of D. fastidiosa gen. nov., sp. nov., the type species of Dielma gen. nov. This bacterium is a Gram-negative, anaerobic, catalase and indole-negative bacillus, isolated from the stool of a healthy Senegalese patient as part of a study aimed at cultivating individually all species within human feces $[1,2]$. The conventional genotypic methods used in bacterial taxonomy include $16 \mathrm{~S}$ rRNA gene-based phylogeny and nucleotide similarity $[3,4]$, determination of the $\mathrm{G}+\mathrm{C}$ content and DNA-DNA hybridization (DDH) [5,6]. Although DDH and 16S rRNA gene similarity cutoffs are considered as gold standards in bacterial taxonomy, they have some limitations as they do not apply well to all species or genera [3]. Hence, there is a need for alternative methods. The introduction of high-throughput genome sequencing and proteomic analyses [7] provided a source of comprehensive information about studied bacterial isolates. Such data may now be included among the criteria used for taxonomic identification. We recently proposed to use a polyphasic approach to describe new bacterial taxa that is based on their genome sequence, MALDI-TOF spectrum and main phenotypic characteristics [8-26].

Here we present a summary classification and a set of features for $D$. fastidiosa gen. nov., sp. nov. strain JC13 $^{\mathrm{T}}$ (CSUR P149 / DSM 26099) together with the description of the complete genome sequencing and annotation. These characteristics support the circumscription of the genus Dielma and its type species, $D$. fastidiosa within the family Erysipelotrichaceae.

The family Erysipelotrichaceae was created in 2004 [27] and includes the 10 following genera: Allobaculum [28], Bulleidia [29], Catenibacterium [30], Coprobacillus (Kageyama and Benno 2000) [30], Eggerthia [31], Erysipelothrix [32], Holdemania [33], Kandleria [31], Solobacterium [30] and Turicibacter [34]. Currently, 12 species with validly published names are reported in this family [35]. The species listed in the Erysipelotrichaceae are mostly comprised of Grampositive, non-spore forming, rod-shaped, straight or slightly curved or irregularly shaped, facultatively anaerobic or anaerobic, catalase negative, chemoorganotrophic fermentative or respiratory metabolism, acidifying glucose and other sugars [35]. Members of species within the radiation of Erysipelotrichaceae were identified as pathogens in both humans and animals. In humans, these bacteria were isolated from patients with oral infection and acute appendicitis [36-40].

\section{Classification and features}

A stool sample was collected from a healthy 16year-old male Senegalese volunteer patient living in Dielmo (rural village in the Guinean-Sudanian zone in Senegal), who was included in a research 
Ramasamy et al.

protocol. Written assent was obtained from this individual. For this study, no written consent was needed from his guardians because he was older than 15 years (in accordance with the previous project approved by the Ministry of Health of Senegal and the assembled village population and as published elsewhere [41].) Both this study and the assent procedure were approved by the National Ethics Committee of Senegal (CNERS) and the Ethics Committee of the Institut Fédératif de Recherche IFR48, Faculty of Medicine, Marseille, France (agreement numbers 09-022 and 11-017 Several other new bacterial species were isolated from this specimen using various culture conditions, including the recently described Alistipes senegalensis, Alistipes timonensis, Anaerococcus senegalensis,Clostridium senegalense, Peptoniphilus timonensis, Paenibacillus senegalensis, Herbaspirillum massiliense, Kurthia massiliensis, Brevibacterium senegalense, Aeromicrobium massilense, Cellulomonas massiliensis, Senegalemassilia anaerobia, Peptoniphilus senegalensis and Enterobacter massiliensis [920,23].

The fecal specimen was preserved at $-80^{\circ} \mathrm{C}$ after collection. Strain JC13 ${ }^{\mathrm{T}}$ (Table 1) was isolated in January 2011 by cultivation on Brain Heart Infusion agar (Becton Dickinson, Pont de Claix, France), after a 10 day preincubation in anaerobic blood culture bottle.

The 16S rRNA sequence (GenBank accession number JF824807) of D. fastidiosa strain $\mathrm{JC13}^{\mathrm{T}}$ was compared to sequences in GenBank using BLAST [50] and showed a highest similarity of $89.71 \%$ with Clostridium innocuum (Figure 1). By comparison with type species from genera within the family Erysipelotrichaceae, D. fastidiosa exhibited a $16 \mathrm{~S}$ rRNA sequence similarity ranging from 69.90 to $89.71 \%$. Since these values are lower than the 95\% threshold recommended by Stackebrandt and Ebers to delineate new genera without performing $\mathrm{DDH}$ [3], we propose to classify strain $\mathrm{JC} 13^{\mathrm{T}}$ within a novel genus.

Strain $\mathrm{JC} 3^{\mathrm{T}}$ did not exhibit catalase or oxidase activity. Using API Rapid ID 32A, positive reactions were obtained for $\alpha$-fucosidase and pyroglutamic acid arylamidase. Negative reactions were observed for indole production, nitrate reduction, urease, arginine dihydrolase, $\alpha$-galactosidase, $\beta$ galactosidase 6 phosphate, $\alpha$-glucosidase, $\beta$ glucosidase, $\alpha$-arabinosidase, $\beta$-glucuronidase, $\mathrm{N}$ acetyl- $\beta$-glucosaminidase, mannose and raffinose fermentation, glutamic acid decarboxylase, alkanine phospatase, arginine arylamidase, proline arylamidase, leucyl glycine arylamidase, phenylalanine aylamidase, leucine arylamidase, pyroglutamic acid arylamidase, tyrosine arylamidase, alanine arylamidase, glycine arylamidase, histidine arylamidase, glutamyl glutamic acid arylamidase, and serine arylamidase. Using an API 20NE strip, a positive reaction was observed for esculine hydrolysis. No sugar fermentation was observed using API 50CH (Biomerieux). D. fastidiosa is susceptible to amoxicillin, imipenem, metronidazole and ciprofloxacine, but resistant to trimethoprim/sulfamethoxazole, rifampin, doxycycline, and gentamicin. The differential phenotypic characteristics with other species are summarized in Table 2 .

Different growth temperatures $\left(25,30,37,45^{\circ} \mathrm{C}\right)$ were tested; growth occurred between $25^{\circ} \mathrm{C}$ and $45^{\circ} \mathrm{C}$ and optimal growth was observed at $30^{\circ} \mathrm{C}$. Colonies were 0.5 to $1 \mathrm{~mm}$ in diameter on bloodenriched Columbia agar and BHI agar. Growth of the strain was tested under anaerobic and microaerophilic conditions using GENbag anaer and GENbag microaer systems, respectively (BioMérieux) and in the presence of air with or without $5 \% \mathrm{CO}_{2}$. Growth was achieved only under anaerobic conditions. Gram staining showed a rodshaped Gram-negative bacterium (Figure 2). The motility test was positive. Cells grown on agar have a mean diameter of $0.60 \mu \mathrm{m}$ and a mean length of $2.2 \mu \mathrm{m}$ in electron microscopy (Figure 3).

Matrix-assisted laser-desorption/ionization timeof-flight (MALDI-TOF) MS protein analysis was carried out as previously described using a Microflex spectrometer (Bruker Daltonics, Leipzig, Germany) $[7,51]$. Briefly, a pipette tip was used to pick one isolated bacterial colony from a cultured agar plate, and spread it as a thin film on a MTP 384 MALDITOF target plate (Bruker Daltonics). Twelve distinct deposits were made for strain JC13 from twelve isolated colonies. Each smear was overlaid with $2 \mu \mathrm{L}$ of matrix solution (saturated solution of alpha-cyano-4-hydroxycinnamic acid) in 50\% acetonitrile, $2.5 \%$ tri-fluoracetic-acid, and allowed to dry for five minutes. Measurements were performed with a Microflex spectrometer (Bruker). Spectra were recorded in the positive linear mode for the mass range of 2,000 to 20,000 Da (parameter settings: ion source 1 (IS1), $20 \mathrm{kV}$; IS2, $18.5 \mathrm{kV}$; lens, $7 \mathrm{kV}$ ). A spectrum was obtained after 675 shots at a variable laser power. The time of acquisi- 
tion was between 30 seconds and 1 minute per spot. The twelve JC13 spectra were imported into the MALDI BioTyper software (version 2.0, Bruker) and analyzed by standard pattern matching (with default parameter settings) against the reference spectra from 4,334 bacteria (as updated on August 29, 2012), including spectra from 17 species within the Erysipelotrichaceae, contained in the BioTyper database. The method of identification included the $\mathrm{m} / \mathrm{z}$ from 3,000 to 15,000 Da. For every spectrum, a maximum of 100 peaks were taken into account and compared with spectra in the database. A score enabled the identification, or not, from the tested species: a score $>2$ with a validly published species enabled the identification at the species level, a score $>1.7$ but $<2$ enabled the identification only at the genus level; and a score $<1.7$ did not enable any identification. For strain JC13 ${ }^{\mathrm{T}}$, no significant score was obtained, suggesting that our isolate was not a member of any known species or genus in the Biotyper database. We incremented our database with the spectrum from strain $\mathrm{JC}^{\mathrm{T}} \mathrm{3}^{\mathrm{T}}$ (Figure 4). The gel view allowed us to highlight the spectra differences with other species of Erysipelothrichaceae family members (Figure 5).

Table 1. Classification and general features of Dielma fastidiosa strain JC13

\begin{tabular}{|c|c|c|c|}
\hline MIGS ID & Property & Term & Evidence code $^{\mathrm{a}}$ \\
\hline & \multirow{8}{*}{ Current classification } & Domain Bacteria & TAS [42] \\
\hline & & Phylum Firmicutes & TAS [43-45] \\
\hline & & Class Erysipelotrichia & TAS $[46,47]$ \\
\hline & & Order Erysipelotrichales & TAS $[47,48]$ \\
\hline & & Family Erysipelotrichaceae & TAS [27] \\
\hline & & Genus Dielma & IDA \\
\hline & & Species Dielma fastidiosa & IDA \\
\hline & & Type strain JC13 ${ }^{\mathrm{T}}$ & IDA \\
\hline & Gram stain & Negative & IDA \\
\hline & Cell shape & Rod & IDA \\
\hline & Motility & Motile & IDA \\
\hline & Sporulation & Non-sporulating & IDA \\
\hline & Temperature range & Mesophile & IDA \\
\hline & Optimum temperature & $37^{\circ} \mathrm{C}$ & IDA \\
\hline MIGS-6.3 & Salinity & Unknown & IDA \\
\hline \multirow[t]{3}{*}{ MIGS-22 } & Oxygen requirement & Anaerobic & IDA \\
\hline & Carbon source & Unknown & \\
\hline & Energy source & Unknown & \\
\hline MIGS-6 & Habitat & Human gut & IDA \\
\hline MIGS-15 & Biotic relationship & Free living & IDA \\
\hline \multirow[t]{3}{*}{ MIGS-14 } & Pathogenicity & Unknown & \\
\hline & Biosafety level & 2 & \\
\hline & Isolation & Human feces & \\
\hline MIGS-4 & Geographic location & Senegal & IDA \\
\hline MIGS-5 & Sample collection time & September 2010 & IDA \\
\hline MIGS-4.1 & Latitude & 13.7167 & IDA \\
\hline MIGS-4.1 & Longitude & -16.4167 & IDA \\
\hline MIGS-4.3 & Depth & Surface & IDA \\
\hline MIGS-4.4 & Altitude & $51 \mathrm{~m}$ above sea level & IDA \\
\hline
\end{tabular}

Evidence codes - IDA: Inferred from Direct Assay; TAS: Traceable Author Statement (i.e., a direct report exists in the literature); NAS: Non-traceable Author Statement (i.e., not directly observed for the living, isolated sample, but based on a generally accepted property for the species, or anecdotal evidence). These evidence codes are from the Gene Ontology project [49]. If the evidence is IDA, then the property was directly observed for a live isolate by one of the authors or an expert mentioned in the acknowledgements. 


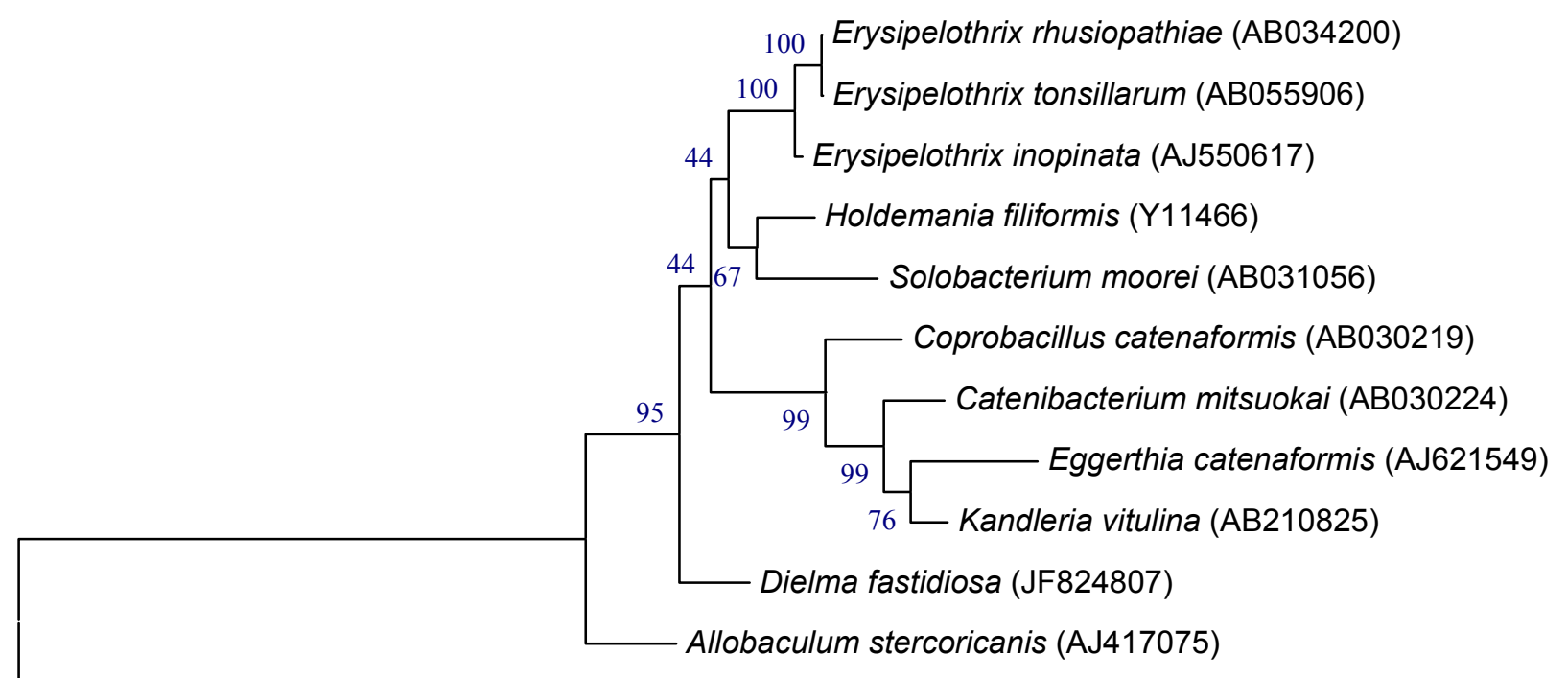

Clostridium innocuum (M23732)

Figure 1. Phylogenetic tree highlighting the position of $D$. fastidiosa strain $\mathrm{JC} 113^{\top}$ relative to other type strains within the Erysipelotrichaceae family. GenBank accession numbers are indicated in parentheses. Sequences were aligned using CLUSTALW, and phylogenetic inferences obtained using the maximum-likelihood method within the MEGA software. Numbers at the nodes are percentages of bootstrap values obtained by repeating the analysis 500 times to generate a majority consensus tree. C. innocuum was used as outgroup. The scale bar represents a $1 \%$ nucleotide sequence divergence.

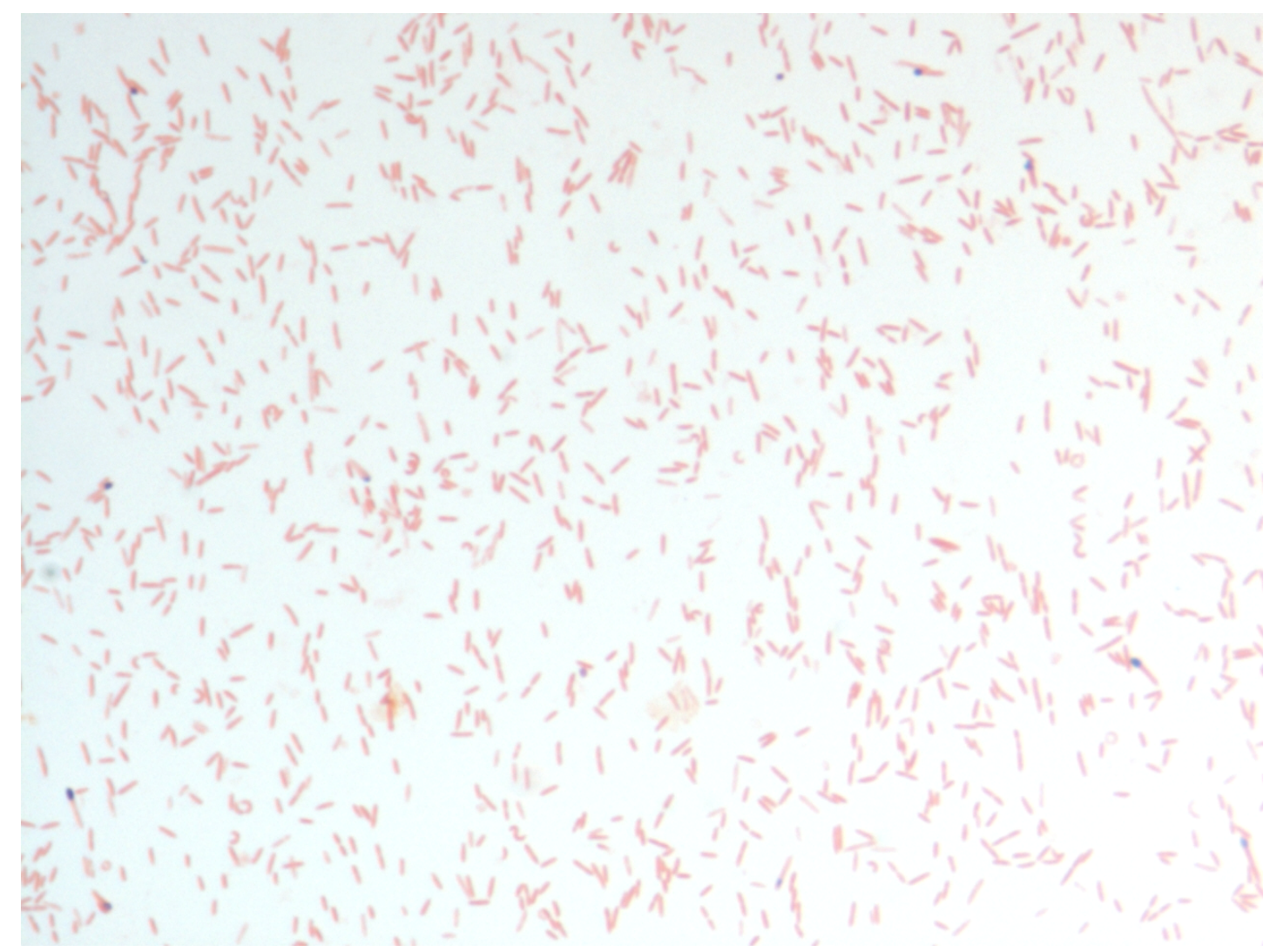

Figure 2. Gram staining of $D$. fastidiosa strain $\mathrm{JC}^{\mathrm{T}} 3^{\mathrm{T}}$ 
Dielma fastidiosa gen. nov., sp. nov.

Table 2. Differential characteristics of Dielma fastidiosa strain JC13 ${ }^{\top}$, Erysipelothrix inopinata strain MF-EP02, Holdemania filiormis strain ATCC51649 ${ }^{\top}$, Eggerthia catenaformis strain JCM1121 ${ }^{\top}$, Kandleria vitulina strain JCM1143 ${ }^{\mathrm{T}}$

\begin{tabular}{llllll}
\hline Properties & $D$. fastidiosa & E. inopinata & $H$. filiformis & E. catenaformis & $K$. vitulina
\end{tabular}

Cell diameter $(\mu \mathrm{m})$

0.60

0.5

na

na

na

Oxygen requirement

anaerobic facultative anaerobic anaerobic

anaerobic

anaerobic

Gram stain

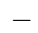

$+$

$+$

$+$

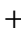

Motility

\section{Production of}

Acid arylamidase

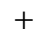

$+$

na

na

na

Catalase

Oxidase

Nitrate reductase

- na

na

na

na

Urease

- na

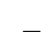

na

na

$\beta$-galactosidase

- na

na

na

na

$\mathrm{N}$-acetyl-glucosamine

- +

na

na

na

na

na

na

\section{Acid from}

L-Arabinose

Ribose

W

Mannose

Mannitol

Sucrose

D-glucose

- na

D-fructose

D-maltose

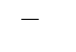

na

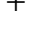

$+$

W

$-$

$-$

D-lactose

\section{Hydrolysis of}

Esculin

$+$

na

$\mathrm{G}+\mathrm{C}$ content $(\mathrm{mol} \%)$

40.0

37.5

na

34.8

34.4

Habitat

human gut

Vegetable broth

Human gut

Human gut

Bovine rumen 


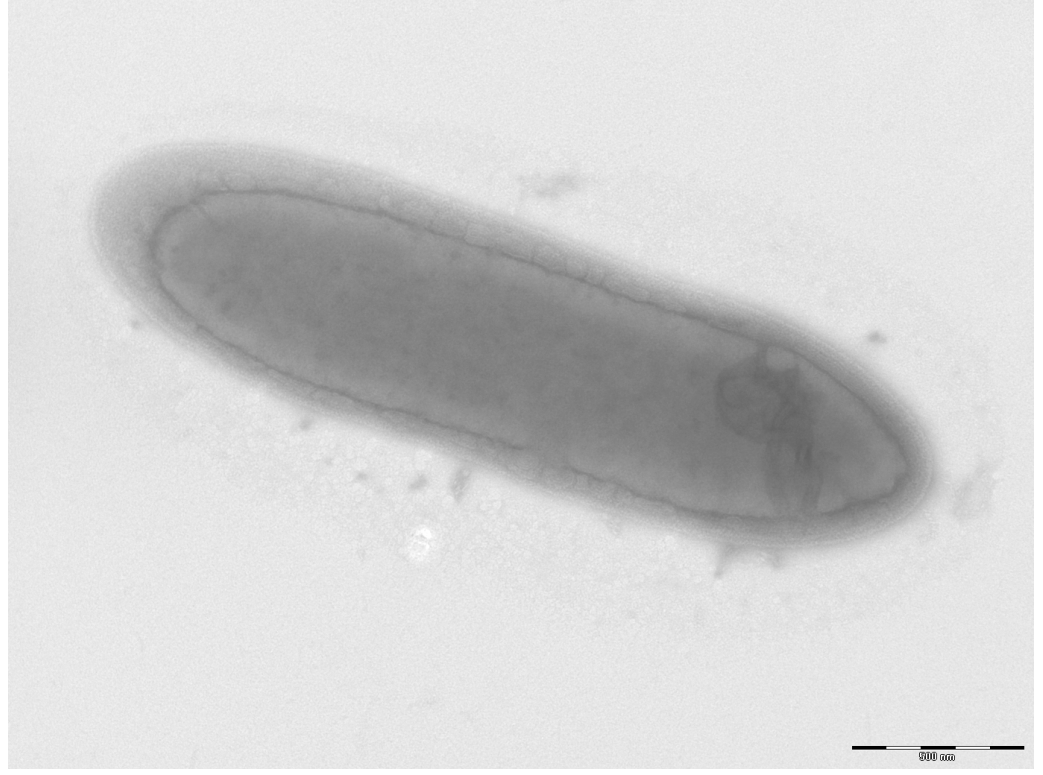

Figure 3. Transmission electron microscopy of D. fastidiosa strain JC13, using a Morgani 268D (Philips) at an operating voltage of 60kV. The scale bar represents $500 \mathrm{~nm}$.

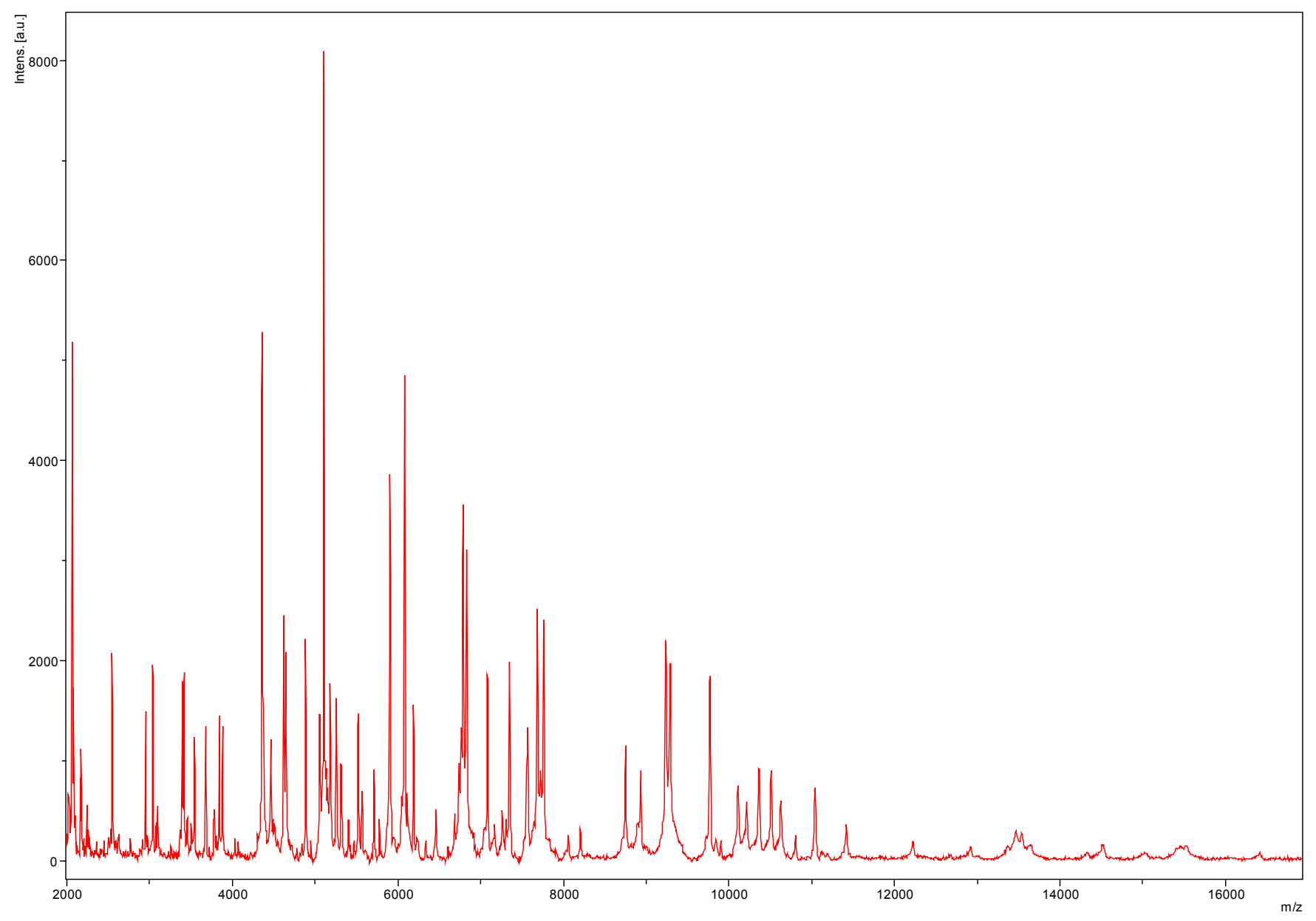

Figure 4. Reference mass spectrum from $D$. fastidiosa strain $\mathrm{JC} 13^{\top}$. Spectra from 12 individual colonies were compared and a reference spectrum was generated. 


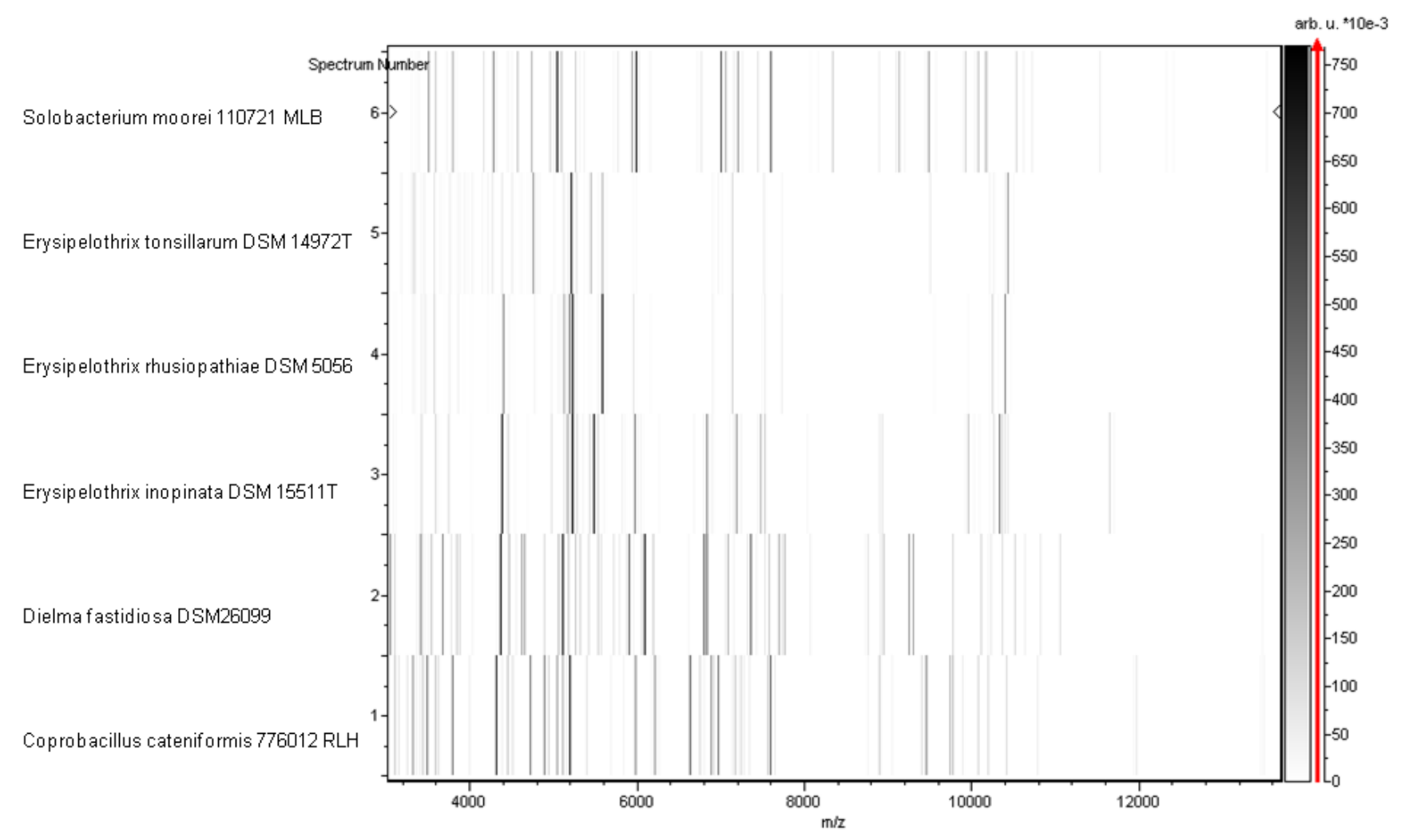

Figure 5. Gel view comparing $D$. fastidiosa gen. nov. sp. nov strain $\mathrm{JC} 13^{\top}$ and other species within Erysipelotrichaceae family. The gel view displays the raw spectra of loaded spectrum files arranged in a pseudo-gel like look. The $x$-axis records the $\mathrm{m} / \mathrm{z}$ value. The left $\mathrm{y}$-axis displays the running spectrum number originating from subsequent spectra loading. The peak intensity is expressed by a Gray scale scheme code. The color bar and the right $y$-axis indicate the relation between the color a peak is displayed with and the peak intensity in arbitrary units. Displayed species are indicated on the left.

\section{Genome sequencing information}

\section{Genome project history}

The organism was selected for sequencing on the basis of its phylogenetic position and 16S rRNA similarity to members of the family Erysipelotrichaceae and is part of a study of the human digestive flora aiming at isolating all bacterial species within human feces [1]. It was the seventh genome from the Erysipelotrichaceae family and the first genome of Dielma fastidiosa gen. nov., sp. nov. The Genbank accession number is CAEN00000000 and consists of 82 contigs. Table 3 shows the project information and its association with MIGS version 2.0 compliance [52]

\section{Growth conditions and DNA isolation}

Dielma fastidiosa sp. nov., strain $\mathrm{JC}^{2} 3^{\mathrm{T}}$ (= CSUR $\mathrm{P} 149$ = DSM 26099) was grown on 5\% sheep blood-enriched Columbia agar at $30^{\circ} \mathrm{C}$ in anaerobic atmosphere. Seven petri dishes were spread and the cultivated bacteria were resuspended in $3 \times 100 \mu$ l of G2 buffer (EZ1 DNA Tissue kit, Qiagen). A first mechanical lysis was performed with glass powder on a Fastprep-24 device (MP Biomedicals, USA) using $2 \times 20$ seconds cycles. DNA was then treated with $2.5 \mu \mathrm{g} / \mu \mathrm{L}$ lysozyme for 30 minutes at $37^{\circ} \mathrm{C}$ and extracted through the BioRobot EZ1 Advanced XL (Qiagen). The DNA was then concentrated and purified with a QIAamp kit (Qiagen). The yield and concentration was measured using a Quant-it Picogreen kit (Invitrogen) on a GeniosTecan fluorometer at 46.6ng/ $\mu \mathrm{l}$.

\section{Genome sequencing and assembly}

DNA $(5 \mu \mathrm{g})$ was mechanically fragmented with a Hydroshear device (Digilab, Holliston, MA, USA) with an enrichment size at 3-4kb. The DNA fragmentation was visualized through the Agilent 
2100 BioAnalyzer on a DNA labchip 7500 with an optimal size of $3.4 \mathrm{~kb}$. The library was constructed according to the 454 GS FLX Titanium paired-end protocol (Roche). Circularization and nebulization were performed. After PCR amplification through 15 cycles followed by double size selection, the single stranded paired-end library profile was visualized on an Agilent 2100 RNA Pico 6000 Labchip with an optimal length of $522 \mathrm{bp}$. Then the library was quantified on the Quant-it Ribogreen kit (Invitrogen) on a GeniosTecan fluorometer at $133 \mathrm{pg} / \mu \mathrm{L}$. The library concentration equivalence was calculated as $4.67 \mathrm{E}+08 \mathrm{~mol}-$ ecules $/ \mu \mathrm{L}$. The library was stored at $-20^{\circ} \mathrm{C}$ until further use.

The shotgun library was clonally amplified with $0.5 \mathrm{cpb}$ in 4 emPCR reactions and $1 \mathrm{cpb}$ in $4 \mathrm{emPCR}$ reactions with the GS Titanium SV emPCR Kit (LibL) v2 (Roche). The yields of the emPCRs were $5.10 \%$ and $10.73 \%$, respectively, in the range of 5 to $20 \%$ recommended by the Roche procedure. Twice, approximately 790,000 beads were loaded on a GS Titanium PicoTiterPlate PTP Kit $70 \times 75$ and sequenced with the GS Titanium Sequencing Kit XLR70 (Roche). The runs were performed overnight and analyzed on the cluster through the gsRunBrowser and Newbler assembler (Roche). A total of 428,372 passed filter wells were obtained and generated $101.3 \mathrm{Mb}$ of sequences with an average of length of $219 \mathrm{bp}$. The passed filter sequences were assembled using Newbler (Roche) with 90\% identity and $40 \mathrm{bp}$ as overlap. The final assembly identified 22 scaffolds and 82 large contigs $(>1,500 \mathrm{bp})$, and generated a genome size of
$3.57 \mathrm{Mb}$ which corresponds to a coverage of $28.92 \mathrm{x}$ genome equivalent.

\section{Genome annotation}

Open reading frames (ORFs) were predicted using Prodigal [53] with default parameters. However, the predicted ORFs were excluded if they spanned a sequencing gap region. The predicted bacterial protein sequences were searched against the GenBank [54] and Clusters of Orthologous Groups (COG) databases using BLASTP. The tRNAs and rRNAs were predicted using the tRNAScanSE [55] and RNAmmer [56] tools, respectively. Lipoprotein signal peptides and numbers of transmembrane helices were predicted using SignalP [57] and TMHMM [58], respectively. ORFans were identified if their BLASTP $E$-value was lower than 1e-03 for alignment length greater than 80 amino acids. If alignment lengths were smaller than 80 amino acids, we use an $E$-value of 1e-05. Such parameter thresholds have already been used in previous works to define ORFans. Artemis [59] and DNA Plotter [60] were used for data management and visualization of genomic features, respectively. The Mauve alignment tool (version 2.3.1) was used for multiple genomic sequence alignment [61]. To estimate the mean level of nucleotide sequence similarity at the genome level between $D$. fastidiosa $\mathrm{JC}^{\mathrm{C}} \mathrm{3}^{\mathrm{T}}$ and another 6 genomes from members of the Erysipelotrichaceae family (Table 4), orthologous proteins were detected using the Proteinortho [62] and we compared genomes two by two and determined the mean percentage of nucleotide sequence identity among orthologous ORFs using BLASTn.

Table 3. Project information

\begin{tabular}{lll}
\hline MIGS ID & Property & Term \\
\hline MIGS-31 & Finishing quality & High-quality draft \\
MIGS-28 & Libraries used & 454 GS paired-end 3- kb libraries \\
MIGS-29 & Sequencing platform & 454 GS FLX Titanium \\
MIGS-31.2 & Sequencing coverage & 28.92× \\
MIGS-30 & Assemblers & gsAssembler \\
MIGS-32 & Gene calling method & PRODIGAL \\
& Genbank Date of Release & December 19, 2012 \\
& NCBI project ID & CAEN00000000 \\
MIGS-13 & Project relevance & Study of the human gut microbiome \\
\hline
\end{tabular}

http://standardsingenomics.org 
Table 4. Genomic comparison of D. fastidiosa $\mathrm{JC} 13^{\top}$ with six other members of Erysipelotrichaceae family

\begin{tabular}{|c|c|c|c|c|}
\hline Species & Strain & Genome accession number & Genome Size $(\mathrm{Mb})$ & $\mathrm{G}+\mathrm{C}$ content $\%$ \\
\hline Dielma fastidiosa & $\mathrm{JC} 13^{\mathrm{T}}$ & CAEN00000000 & $3,575,363$ & 40.00 \\
\hline Erysipelothrix rhusiopathiae & Fujisawa & NC_015601 & $1,787,941$ & 36.60 \\
\hline Holdemania filiformis & DSM 12042 & NZ_ACCF00000000 & $3,803,745$ & 50.20 \\
\hline Bulleidia extructa & W1219 & NZ_ADFR00000000 & 3,170963 & 36.20 \\
\hline Catenibacterium mitsuokai & DSM 15897 & NZ_ACCK00000000 & 4,835437 & 36.80 \\
\hline Solobacterium moorei & F0204 & NZ_AECQ00000000 & $4,403,767$ & 36.80 \\
\hline Turicibacter sanguinis & PC909 & NZ_ADMN00000000 & $2,953,411$ & 34.10 \\
\hline
\end{tabular}

\section{Genome properties}

The genome is $3,574,031 \mathrm{bp}$ long (one chromosome of $3,556,241 \mathrm{bp}$ and one plasmid of 17,790 bp) with a GC content of $40.00 \%$ (Figure 6 and Table 5). Of the 3,491 predicted chromosomal genes, 3,441 were protein-coding genes and 50 were RNAs. A total of 2,534 genes (72.58\%) were assigned a putative function. ORFans accounted for 269 genes $(7.81 \%)$ and the remaining genes were annotated as hypothetical proteins. The properties and statistics of the genome are summarized in Tables 5 and 6. The distribution of genes into COGs functional categories is presented in Table 6. The 17,790bp-long plasmid contains 17 protein-coding genes. A BLASTN search showed its closest match to be the DO plasmid from Enterococcus faecium (GenBank Accession number: NC017961).

\section{Genome comparison of $D$. fastidiosa with} other genomes of Erysipelotrichaceae family Here, we compared the genome of $D$. fastidiosa JC13T with 6 other genomes from
Erysipelotrichaceae family (Table 3 and 6). D. fastidiosa $(3.57 \mathrm{Mb})$ is larger than those of $E$. rhusiopathiae, B. extructa and T. sanguinis (1.78, 3.17 and $2.95 \mathrm{Mb}$ respectively) but smaller than those of $H$. filiformis, C. mitsuokai and S. moorei (3.80, 4.83 and $4.40 \mathrm{Mb}$ respectively). The $\mathrm{G}+\mathrm{C}$ content of $D$. fastidiosa is higher $(40.0 \%)$ than all the genomes compared except $H$. filiformis $(50.2 \%)$. D. fastidiosa has more predicted genes than $S$. moorei and $T$. sanguinis $(2,619,2,342$ and 2,335 respectively) but less than those of $E$. rhusiopathiae, $H$. filiformis, B. extructa and C. mitsuokai $(2,709,3,161,3,132$ and 3,231, respectively). In addition, $D$. fastidiosa shared 681, 1,005, $650,804,824$ and 781 orthologous genes with $E$. rhusiopathiae, $H$. filiformis, $B$. extructa, $C$. mitsuokai, S. moorei and T. sanguinis respectively. The average nucleotide sequence identity ranged from 61.12 to $69.65 \%$ among Erysipelotrichaceae family species, and from 64.29 to $65.99 \%$ between D. fastidiosa and other species, thus confirming its new species status (Table 7). 


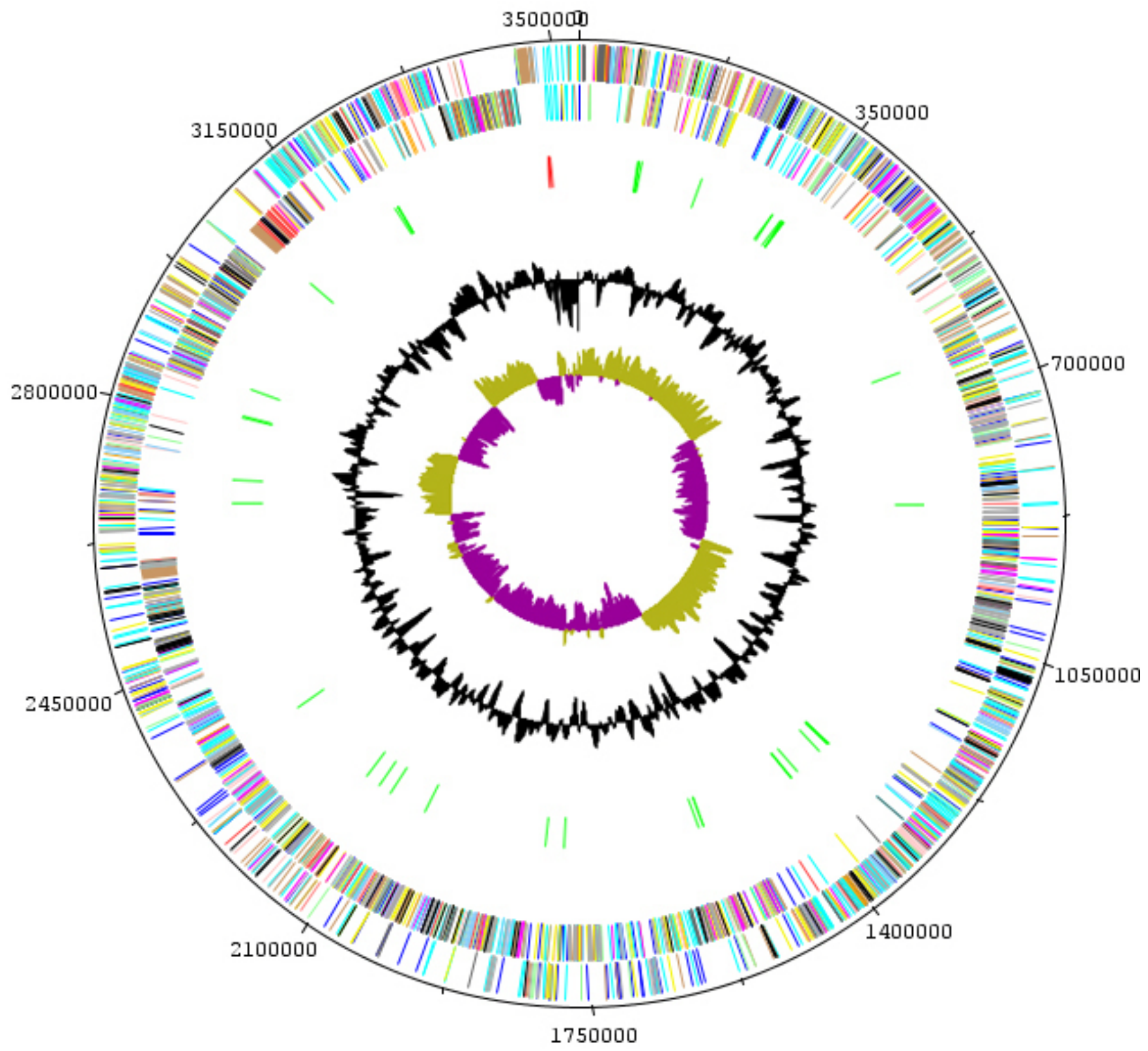

Figure 6. Graphical circular map of the chromosome. From outside to the center: Genes on the forward strand (colored by COG categories), genes on the reverse strand (colored by COG categories), RNA genes (tRNAs green, rRNAs red), GC content, and GC skew. 
Table 5. Nucleotide content and gene count levels of the chromosome

\begin{tabular}{lrr}
\hline Attribute & Value & \% of total $^{\mathbf{a}}$ \\
\hline Genome size (bp) & $3,556,241$ & \\
DNA coding region (bp) & $3,170,580$ & 89.15 \\
DNA G+C content (bp) & $1,422,496$ & 40.0 \\
Total genes & 3,491 & 100 \\
RNA genes & 50 & 1.43 \\
Protein-coding genes & 3,441 & 98.56 \\
Genes with function prediction & 2,534 & 72.58 \\
Genes assigned to COGs & 2,329 & 66.71 \\
Genes with peptide signals & 259 & 7.41 \\
Genes with transmembrane helices & 905 & 25.62 \\
\hline
\end{tabular}

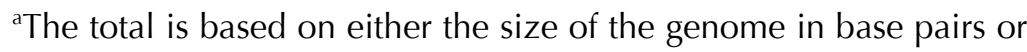
the total number of protein coding genes in the annotated genome

Table 6. Number of genes associated with the 25 general COG functional categories

\begin{tabular}{crrl}
\hline Code & Value & \%age $^{\mathbf{a}}$ & Description \\
\hline J & 149 & 4.33 & Translation \\
A & 1 & 0.029 & RNA processing and modification \\
K & 163 & 4.73 & Transcription \\
L & 176 & 5.11 & Replication, recombination and repair \\
B & 0 & 0 & Chromatin structure and dynamics \\
D & 24 & 0.69 & Cell cycle control, mitosis and meiosis \\
Y & 0 & 0 & Nuclear structure \\
V & 47 & 1.36 & Defense mechanisms \\
T & 52 & 1.511 & Signal transduction mechanisms \\
M & 105 & 3.05 & Cell wall/membrane biogenesis \\
N & 0 & 0 & Cell motility \\
Z & 0 & 0 & Cytoskeleton \\
W & 0 & 0 & Extracellular structures \\
U & 26 & 0.75 & Intracellular trafficking and secretion \\
O & 76 & 2.20 & Posttranslational modification, protein turnover, chaperones \\
C & 139 & 4.03 & Energy production and conversion \\
G & 88 & 2.55 & Carbohydrate transport and metabolism \\
E & 189 & 5.49 & Amino acid transport and metabolism \\
F & 63 & 1.83 & Nucleotide transport and metabolism \\
H & 72 & 2.09 & Coenzyme transport and metabolism \\
I & 123 & 3.57 & Lipid transport and metabolism \\
P & 127 & 3.69 & Inorganic ion transport and metabolism \\
Q & 25 & 0.72 & Secondary metabolites biosynthesis, transport and catabolism \\
R & 250 & 7.26 & General function prediction only \\
S & 182 & 5.28 & Function unknown \\
- & 301 & 8.74 & Not in COGs \\
\hline & & & \\
\hline
\end{tabular}

${ }^{a}$ The total is based on the total number of protein coding genes in the annotated genome 
Table 7. The numbers of orthologous protein shared between genomes (above diagonal), average percentage similarity of nucleotides corresponding to orthologous protein shared between genomes (below diagonal) and the numbers of proteins per genome (bold).

\begin{tabular}{|c|c|c|c|c|c|c|c|}
\hline Species & D. fastidiosa & E. rhusiopathiae & H. filiformis & B. extructa & C. mitsuokai & S. moorei & T. sanguinis \\
\hline $\begin{array}{l}\text { Dielma } \\
\text { fastidiosa }\end{array}$ & 2,619 & 681 & 1,005 & 650 & 804 & 824 & 781 \\
\hline $\begin{array}{l}\text { Erysipelothrix } \\
\text { rhusiopathiae }\end{array}$ & 64.99 & 2,709 & 650 & 534 & 553 & 597 & 563 \\
\hline $\begin{array}{l}\text { Holdemania } \\
\text { filiformis }\end{array}$ & 65.99 & 62.24 & 3,161 & 661 & 761 & 808 & 749 \\
\hline $\begin{array}{l}\text { Bulleidia } \\
\text { extructa }\end{array}$ & 64.89 & 65.24 & 62.84 & 3,132 & 539 & 745 & 524 \\
\hline $\begin{array}{l}\text { Catenibacteri } \\
\text { um mitsuokai }\end{array}$ & 65.13 & 65.13 & 61.12 & 65.13 & 3,231 & 649 & 659 \\
\hline $\begin{array}{l}\text { Solobacterium } \\
\text { moorei }\end{array}$ & 65.16 & 65.54 & 63.13 & 69.65 & 66.18 & 2,342 & 614 \\
\hline $\begin{array}{l}\text { Turicibacter } \\
\text { sanguinis }\end{array}$ & 64.29 & 65.37 & 64.62 & 64.76 & 65.89 & 64.62 & 2,335 \\
\hline
\end{tabular}

\section{Conclusion}

On the basis of phenotypic, phylogenetic and genome analysis, we formally propose the creation of Dielma fastidiosa gen nov., sp. nov., that contains strain JC13 ${ }^{\mathrm{T}}$. This strain has been found in Senegal.

\section{Description of Dielma gen. nov.}

Dielma (di.el'ma, N.L. fem. N. Dielma, of Dielmo, the Senegalese village where lived the patient from whom strain $\mathrm{JC}^{2} 3^{\mathrm{T}}$ was cultivated).

Gram-negative rods. Strictly anaerobic. Mesophilic. Motile. Negative for catalase, oxidase, nitrate reduction and indole production. Positive for $\alpha$-fucosidase, pyroglutamic acid arylamidase and esculine hydrolysis. Habitat: human digestive tract. Type species: Dielma fastidiosa.

\section{Description of Dielma fastidiosa sp. nov., gen nov.}

Dielma fastidiosa (fas.ti.di.o'sa. N. L. F. adj. from the Latin adjective fastidiosus excessively sensitive; referring to the difficulty to isolate this $\mathrm{mi}-$ croorganism). It has been isolated from feces from an asymptomatic Senegalese patient.
Dielma fastidiosa is an anaerobic Gram-negative bacterium. Growth is achieved only anaerobically. Growth occurs on axenic medium between 25 and $45^{\circ} \mathrm{C}$, with optimal growth observed at $30^{\circ} \mathrm{C}$. Cells stain Gram-negative, are rod-shaped, nonsporulating, motile and have a mean diameter of $0.60 \mu \mathrm{m}$ and a mean length of $2.2 \mu \mathrm{m}$. Colonies are 0.5 to $1 \mathrm{~mm}$ in diameter on blood-enriched Columbia agar. Oxidase negative. Catalase negative. Using the API Rapid ID 32A system, positive reactions are obtained for $\alpha$-fucosidase and pyroglutamic acid arylamidase. Negative reactions for indole production, nitrate reduction, urease, arginine dihydrolase, $\alpha$-galactosidase, $\beta$ galactosidase 6 phosphate, $\alpha$-glucosidase, $\beta$ glucosidase, $\alpha$-arabinosidase, $\beta$-glucuronidase, $\mathrm{N}$ acetyl- $\beta$-glucosaminidase, mannose and raffinose fermentation, glutamic acid decarboxylase, alkanine phospatase, arginine arylamidase, proline arylamidase, leucyl glycine arylamidase, phenylalanine aylamidase, leucine arylamidase, pyroglutamic acid arylamidase, tyrosine arylamidase, alanine arylamidase, glycine arylamidase, histidine arylamidase, glutamyl 
glutamic acid arylamidase, and serine arylamidase. With the API 20NE system, a positive reaction is observed for aesculin. Asaccharolytic. D. fastidiosa is susceptible to amoxicillin, imipenem, metronidazole and ciprofloxacin, but resistant to trimethoprim/sulfamethoxazole, rifampin, doxycycline and gentamicin.

\section{Acknowledgements}

The authors thank the Xegen Company (www.xegen.fr) for automating the genomic annotation process. This

\section{References}

1. Lagier JC, Armougom F, Million M, Hugon P, Pagnier I, Robert C, Bittar F, Fournous G, Gimenez G, Maraninchi M, et al. Microbial culturomics: paradigm shift in the human gut microbiome study. Clin Microbiol Infect 2012; 18:1185-1193. PubMed

2. Dubourg G, Lagier JC, Armougom F, Robert C, Hamad I, Brouqui P. The gut microbiota of a patient with resistant tuberculosis is more comprehensively studied by culturomics than by metagenomics. Eur J Clin Microbiol Infect Dis 2013; 32:637-645. PubMed http://dx.doi.org/10.1007/s10096-012-1787-3

3. Tindall BJ, Rosselló-Móra R, Busse HJ, Ludwig W, Kämpfer P. Notes on the characterization of prokaryote strains for taxonomic purposes. Int I Syst Evol Microbiol 2010; 60:249-266. PubMed http://dx.doi.org/10.1099/ijs.0.016949-0

4. Stackebrandt E, Ebers J. Taxonomic parameters revisited: tarnished gold standards. Microbiol Today 2006; 33:152-155.

5. Wayne LG, Brenner DJ, Colwell RR, Grimont AD, Kandler O, Krichevsky MI, Moore LH, Moore EC, Murray GE, Sktackbrandt E, et al. Report of the ad hoc committee on reconciliation of approaches to bacterial systematic. Int J Syst Bacteriol 1987; 37:463-464. http://dx.doi.org/10.1099/00207713$\underline{37-4-463}$

6. Rossello-Mora R. DNA-DNA Reassociation Methods Applied to Microbial Taxonomy and Their Critical Evaluation. In: Stackebrandt E (ed), Molecular Identification, Systematics, and population Structure of Prokaryotes. Springer, Berlin, 2006, p. 23-50.

7. Welker M, Moore ER. Applications of whole-cell matrix-assisted laser-desorption/ionization timeof-flight mass spectrometry in systematic microbi-
The $\mathrm{G}+\mathrm{C}$ content of the genome is $40 \%$. The $16 \mathrm{~S}$ rRNA and genome sequences are deposited in Genbank and EMBL under accession numbers JF824807 and CAEN00000000, respectively. The type strain is JC13 ${ }^{\mathrm{T}}$ (= CSUR P149 = DSM 26099) was isolated from the fecal flora of a healthy Senegalese patient.

study was funded by the Mediterranee-Infection Foundation.

ology. Syst Appl Microbiol 2011; 34:2-11. Pub-

Med

http://dx.doi.org/10.1016/j.syapm.2010.11.013

8. Kokcha S, Mishra AK, Lagier JC, Million M, Leroy Q, Raoult D, Fournier PE. Non contiguousfinished genome sequence and description of $\mathrm{Ba}$ cillus timonensis sp. nov. Stand Genomic Sci 2012; 6:346-355. PubMed http://dx.doi.org/10.4056/sigs.2776064

9. Lagier JC, El Karkouri K, Nguyen TT, Armougom F, Raoult D, Fournier PE. Non-contiguous finished genome sequence and description of Anaerococcus senegalensis sp. nov. Stand Genomic Sci 2012; 6:116-125. PubMed http://dx.doi.org/10.4056/sigs.2415480

10. Mishra AK, Gimenez G, Lagier JC, Robert C, Raoult D, Fournier PE. Non-contiguous finished genome sequence and description of Alistipes senegalensis sp. nov. Stand Genomic Sci 2012; 6:304-314. http://dx.doi.org/10.4056/sigs.2625821

11. Lagier JC, Armougom F, Mishra AK, Ngyuen TT, Raoult D, Fournier PE. Non-contiguous finished genome sequence and description of Alistipes timonensis sp. nov. Stand Genomic Sci 2012; 6:315-324. PubMed

12. Mishra AK, Lagier JC, Robert C, Raoult D, Fournier PE. Non-contiguous finished genome sequence and description of Clostridium senegalense sp. nov. Stand Genomic Sci 2012; 6:386-395. PubMed

13. Mishra AK, Lagier JC, Robert C, Raoult D, Fournier PE. Non contiguous-finished genome sequence and description of Peptoniphilus timonensis sp. nov. Stand Genomic Sci 2012; 7:111. PubMed http://dx.doi.org/10.4056/sigs.2956294 
14. Mishra AK, Lagier JC, Rivet R, Raoult D, Fournier PE. Non contiguous-finished genome sequence and description of Paenibacillus senegalensis sp. nov. [epub.]. Stand Genomic Sci 2012; 7:70-81. PubMed

15. Lagier JC, Gimenez G, Robert C, Raoult D, Fournier PE. Non-contiguous finished genome sequence and description of Herbaspirillum massiliense sp. nov. Stand Genomic Sci 2012; 7:200-209. PubMed

16. Roux V, El Karkouri K, Lagier JC, Robert C, Raoult $D$. Non-contiguous finished genome sequence and description of Kurthia massiliensis sp. nov. Stand Genomic Sci 2012; 7:221-232. PubMed http://dx.doi.org/10.4056/sigs.3206554

17. Kokcha S, Ramasamy D, Lagier JC, Robert C, Raoult D, Fournier PE. Non-contiguous finished genome sequence and description of Brevibacterium senegalense sp. nov. Stand Genomic Sci 2012; 7:233-245. PubMed http://dx.doi.org/10.4056/sigs.3256677

18. Ramasamy D, Kokcha S, Lagier JC, N'Guyen TT, Raoult D, Fournier PE. Non-contiguous finished genome sequence and description of Aeromicrobium massilense sp. nov. Stand Genomic Sci 2012; 7:246-257. PubMed http://dx.doi.org/10.4056/sigs.3306717

19. Lagier JC, Ramasamy D, Rivet R, Raoult D, Fournier PE. Non-contiguous finished genome sequence and description of Cellulomonas massiliensis sp. nov. Stand Genomic Sci 2012; 7:258-270. PubMed http://dx.doi.org/10.4056/sigs.3316719

20. Lagier JC, El Karkouri K, Rivet R, Couderc C, Raoult D, Fournier PE. Non-contiguous finished genome sequence and description of Senegalemassilia anaerobia sp. nov. Stand Genomic Sci 2013; 7:343-356.

http://dx.doi.org/10.4056/sigs.3246665

21. Mishra AK, Hugon P, Lagier JC, Nguyen TT, Robert C, Couderc C, Raoult D, Fournier PE. Noncontiguous finished genome sequence and description of Peptoniphilus obesi sp. nov. Stand Genomic Sci 2013; 7:357-369. http://dx.doi.org/10.4056/sigs.32766871

22. Mishra AK, Lagier JC, Nguyen TT, Raoult D, Fournier PE. Non-contiguous finished genome sequence and description of Peptoniphilus senegalensis sp. nov. Stand Genomic Sci 2013; 7:370-381. http://dx.doi.org/10.4056/sigs.3366764
23. Lagier JC, El Karkouri K, Mishra AK, Robert C, Raoult D, Fournier PE. Non-contiguous finished genome sequence and description of Enterobacter massiliensis sp. nov. Stand Genomic Sci 2013; 7:399-412. http://dx.doi.org/10.4056/sigs.3396830

24. Hugon P, Ramasamy D, Lagier JC, Rivet R, Couderc C, Raoult D, Fournier PE. Noncontiguous finished genome sequence and description of Alistipes obesi sp. nov. Stand Genomic Sci 2013; 7:427-439. http://dx.doi.org/10.4056/sigs.3336746

25. Mishra AK, Hugon $P$, Robert $C$, Couderc $C$, Raoult D, Fournier PE. Non-contiguous finished genome sequence and description of Peptoniphilus grossensis sp. nov. Stand Genomic Sci 2012; 7:320-330. PubMed

26. Hugon P, Mishra AK, Lagier JC, Nguyen TT, Couderc C, Raoult D, Fournier PE. Noncontiguous finished genome sequence and description of Brevibacillus massiliensis sp. nov. Stand Genomic Sci 2013; 8:1-14. http://dx.doi.org/10.4056/sigs.3466975

27. Verbarg S, Rheims H, Emus S, Frühling A, Kroppenstedt RM, Stackebrandt E, Schumann P. Erysipelothrix inopinata sp. nov., isolated in the course of sterile filtration of vegetable peptone broth, and description of Erysipelotrichaceae fam. nov. Int J Syst Evol Microbiol 2004; 54:221-225. PubMed http://dx.doi.org/10.1099/ijs.0.02898-0

28. Greetham HL, Gibson GR, Giffard C, Hippe H, Merkhoffer B, Steiner U, Falsen E, Collins MD. Allobaculum stercoricanis gen. nov., sp. nov., isolated from canine feces. Anaerobe 2004; 10:301307. PubMed http://dx.doi.org/10.1016/j.anaerobe.2004.06.004

29. Downes J, Olsvik B, Hiom SJ, Spratt DA, Cheeseman SL, Olsen I, Weightman AJ, Wade WG. Bulleidia extructa gen. nov., sp. nov., isolated from the oral cavity. Int I Syst Evol Microbiol 2000; 50:979-983. PubMed http://dx.doi.org/10.1099/00207713-50-3-979

30. Kageyama A, Benno Y. Catenibacterium mitsuokai gen. nov., sp. nov., a gram-positive anaerobic bacterium isolated from human faeces. Int I Syst Evol Microbiol 2000; 50:1595-1599. PubMed http://dx.doi.org/10.1099/00207713-50$\underline{4-1595}$

31. Salvetti E, Felis GE, Dellaglio F, Castioni A, Torriani S, Lawson PA. Reclassification of Lactobacillus catenaformis (Eggerth 1935) Moore and Holdeman 1970 and Lactobacillus vitulinus 
Sharpe et al. 1973 as Eggerthia catenaformis gen. nov., comb. nov. and Kandleria vitulina gen. nov., comb. nov., respectively. Int / Syst Evol Microbiol 2011; 61:2520-2524. PubMed http://dx.doi.org/10.1099/ijs.0.029231-0

32. Skerman (V.B.D.). McGowan (V.) and Sneath (P.H.A.) (editors): Approved Lists of Bacterial Names. Int. J. Syst. Bacteriol., 1980, 30, 225-420.

33. Willems A, Moore WE, Weiss N, Collins MD. Phenotypic and phylogenetic characterization of some Eubacterium-like isolates containing a novel type B wall murein from human feces: description of Holdemania filiformis gen. nov., sp. nov. Int J Syst Bacteriol 1997; 47:1201-1204. PubMed http://dx.doi.org/10.1099/00207713-47-4-1201

34. Bosshard PP, Zbinden R, Altwegg M. Turicibacter sanguinis gen. nov., sp. nov., a novel anaerobic, Gram-positive bacterium. Int I Syst Evol Microbiol 2002; 52:1263-1266. PubMed

http://dx.doi.org/10.1099/ijs.0.02056-0

35. List of Prokaryotic names with standing nomenclature (LPSN). http://www.bacterio.cict.fr.

36. Brooke CJ, Riley TV. Erysipelothrix rhusiopathiae: Bacteriology, epidemiology and clinical manifestations of an occupational pathogen. / Med Microbiol 1999; 48:789-799. PubMed http://dx.doi.org/10.1099/00222615-48-9-789

37. Barber M. Discussion on swine erysipelas infection (Erysipelothrix rhusiopathiae) in man and animals. Proc R Soc Med 1948; 41:328-332. PubMed

38. Downes J, Olsvik B, Hiom SJ, Spratt DA, Cheeseman SL, Olsen I, Weightman AJ, Wade WG. Bulleidia extructa gen. nov., sp. nov., isolated from the oral cavity. Int I Syst Evol Microbiol 2000; 50:979-983. PubMed http://dx.doi.org/10.1099/00207713-50-3-979

39. Takahashi T, Fujisawa $T$, Benno $Y$, Tamura $Y$, Sawada T, Suzuki S, Muramatsu M, Mitsuoka T. Erysipelothrix tonsillarum sp. nov. isolated from tonsils of apparently healthy pigs. Int / Syst Bacteriol 1987; 37:166-168. http://dx.doi.org/10.1099/00207713-37-2-166

40. Allianatos PG, Tilentzoglou AC, Koutsoukou AD. Septic arthritis caused by Erysipelothrix rhusiopathiae infection after arthroscopically assisted anterior cruciate ligament reconstruction. Arthroscopy 2003; 19:26. PubMed http://dx.doi.org/10.1053/jars.2003.50077

41. Trape JF, Tall A, Diagne N, Ndiath O, Ly AB, Faye J, Dieye-Ba F, Roucher C, Bouganali C,
Badiane A, et al. Malaria morbidity and pyrethroid resistance after the introduction of insecticide-treated bednets and artemisinin-based combination therapies: a longitudinal study. Lancet Infect Dis 2011; 11:925-932. PubMed http://dx.doi.org/10.1016/S1473-3099(11)70194$\underline{3}$

42. Woese CR, Kandler O, Wheelis ML. Towards a natural system of organisms: proposal for the domains Archae, Bacteria, and Eukarya. Proc Natl Acad Sci USA 1990; 87:4576-4579. PubMed http://dx.doi.org/10.1073/pnas.87.12.4576

43. Murray RGE. The higher taxa, or, a place for everything...? In: Krieg NR, Holt JG (eds), Bergey's Manual of Systematic Bacteriology, First edition, volume 1, The Williams \& Wilkins Co., Baltimore, 1984, p. 31-34.

44. Gibbons NE, Murray RGE. Proposals concerning the higher taxa of Bacteria. Int / Syst Bacteriol 1978; 28:1-6. http://dx.doi.org/10.1099/00207713-28-1-1

45. Garrity GM, Holt J. The road map to the manual. In: Garrity GM, Boone DR, Castenholz RW (eds), Bergey's Manual of Systematic Bacteriology. Second Edition, Volume 1, Springer, New York, 2001, p.119-169.

46. Ludwig W, Schleifer KH, Whitman WB. Class III. Erysipelotrichia class nov. In: De Vos P, Garrity G, Jones D, Krieg NR, Ludwig W, Rainey FA, Schleifer KH, Whitman WB (eds): Bergey's Manual of Systematic Bacteriology, second edition, vol. 3 (The Firmicutes), Springer, Dordrecht, Heidelberg, London, New York, 2009, p. 1298.

47.List of new names and new combinations previously effectively, but not validly, published. List no. 132. Int J Syst Evol Microbiol 2010; 60:469-472. http://dx.doi.org/10.1099/ijs.0.022855-0

48. Ludwig W, Schleifer KH, Whitman WB. Order I. Erysipelotrichales ord. nov. In: De Vos P, Garrity G, Jones D, Krieg NR, Ludwig W, Rainey FA, Schleifer KH, Whitman WB (eds), Bergey's Manual of Systematic Bacteriology, Second Edition, Volume 3, Springer-Verlag, New York, 2009, p. 1298.

49. Ashburner M, Ball CA, Blake JA, Botstein D, Butler H, Cherry JM, Davis AP, Dolinski K, Dwight SS, Eppig JT, et al. Gene ontology: tool for the unification of biology. The Gene Ontology Consortium. Nat Genet 2000; 25:25-29. PubMed http://dx.doi.org/10.1038/75556 
50. Altschul SF, Gish W, Miller W, Myers EW, Lipman DJ. Basic local alignment search tool. J Mol Biol 1990; 215:403-410. PubMed

51. Seng P, Drancourt M, Gouriet F, La Scola B, Fournier PE, Rolain JM, Raoult D. Ongoing revolution in bacteriology: routine identification of bacteria by matrix-assisted laser desorption ionization time-of-flight mass spectrometry. Clin Infect Dis 2009; 49:543-551. PubMed http://dx.doi.org/10.1086/600885

52. Field D, Garrity G, Gray T, Morrison N, Selengut J, Sterk P, Tatusova T, Thomson N, Allen MJ, Angiuoli SV, et al. The minimum information about a genome sequence (MIGS) specification. Nat Biotechnol 2008; 26:541-547. PubMed http://dx.doi.org/10.1038/nbt1360

53. Prodigal. http://prodigal.ornl.gov/

54. Benson DA, Karsch-Mizrachi I, Clark K, Lipman DJ, Ostell J, Sayers EW. GenBank. Nucleic Acids Res 2012; 40:D48-D53. PubMed http://dx.doi.org/10.1093/nar/gkr1202

55. Lowe TM, Eddy SR. tRNAscan-SE: a program for improved detection of transfer RNA genes in genomic sequence. Nucleic Acids Res 1997;

25:955-964. PubMed

56. Lagesen K, Hallin P, Rodland EA, Staerfeldt HH, Rognes T, Ussery DW. RNAmmer: consistent and rapid annotation of ribosomal RNA genes. Nucleic Acids Res 2007; 35:3100-3108. PubMed http://dx.doi.org/10.1093/nar/gkm160
57. Bendtsen JD, Nielsen H, von Heijne G, Brunak S. Improved prediction of signal peptides: SignalP 3.0. J Mol Biol 2004; 340:783-795. PubMed http://dx.doi.org/10.1016/j.jmb.2004.05.028

58. Krogh A, Larsson B, von Heijne G, Sonnhammer EL. Predicting transmembrane protein topology with a hidden Markov model: application to complete genomes. J Mol Biol 2001; 305:567580. PubMed http://dx.doi.org/10.1006/jmbi.2000.4315

59. Rutherford K, Parkhill J, Crook J, Horsnell T, Rice P, Rajandream MA, Barrell B. Artemis: sequence visualization and annotation. Bioinformatics 2000; 16:944-945. PubMed http://dx.doi.org/10.1093/bioinformatics/16.10.94 $\underline{4}$

60. Carver T, Thomson N, Bleasby A, Berriman M, Parkhill J. DNAPlotter: circular and linear interactive genome visualization. Bioinformatics 2009; 25:119-120. PubMed http://dx.doi.org/10.1093/bioinformatics/btn578

61. Darling AC, Mau B, Blattner FR, Perna NT. Mauve: multiple alignment of conserved genomic sequence with rearrangements. Genome Res 2004; 14:1394-1403. PubMed http://dx.doi.org/10.1101/gr.2289704

62. Lechner M, Findeib S, Steiner L, Marz M, Stadler PF, Prohaska SJ. Proteinortho: Detection of (Co-) orthologs in large-scale analysis. BMC Bioinformatics 2011; 12:124. PubMed http://dx.doi.org/10.1186/1471-2105-12-124 